\title{
Improving the performance of railway track through ballast interventions
}

\author{
Taufan Abadi ${ }^{1}$, Louis Le Pen ${ }^{1}$, Antonis Zervos ${ }^{1}$, William Powrie ${ }^{1}$ \\ ${ }^{1}$ Infrastructure Research Group, University of Southampton; UK
}

This article was accepted for publication by Journal of Rail and Rapid Transit, Proceedings of the institution of the Institution of Mechanical Engineers part F on 16 August, this is the author's non-typeset version of the article. Figures are at the end of the text article.

\section{Corresponding author:}

Taufan Abadi, Infrastructure Research Group, University of Southampton, University Road, Southampton, SO17 1BJ, UK. Email: tc.abadi@soton.ac.uk

\begin{abstract}
Maintenance and eventual renewal of ballasted track constitute major operational costs for a railway network. Thus significant benefits would accrue from a more robust track design having a longer service life and reduced maintenance requirements. This paper presents results from a laboratory study exploring the potential to achieve this through improving the ballast grading and reducing the ballast shoulder slope. Cyclic loading tests were carried out on a section of track representing one sleeper bay in plane strain, in the Southampton Railway testing Facility (SRTF). A cyclic load representing a 20 tonne axle load was applied at $3 \mathrm{~Hz}$ for at least 3 million cycles, during which measurements of permanent and resilient vertical deflection were made. Certain interventions are found to result in lower rates of permanent settlement and different resilient ranges of movement. Supplementary measurements to determine longitudinal pressure, ballast breakage and attrition, and shoulder slope movement were used to explore the mechanisms responsible for the observed improvements in ballast bed performance. It is concluded that the use of finer ballast gradings and a shallower shoulder slope have the potential to reduce maintenance requirements.
\end{abstract}

Keywords

Ballast grading, two layered ballast, re-profiled shoulder slope, ballast settlement 


\section{Introduction}

Recent increases in passenger and freight traffic $^{1-3}$ have led to many railway routes becoming more intensively used than ever before, with a consequent need for more frequent track maintenance. Most of the world's railways are on ballasted track. The volume of the current asset is such that, although new railways may be built using slab track, the dominance of ballasted track is unlikely to change in the foreseeable future. Ballasted track consists essentially of rails, supported by sleepers on a ballast bed. This track form is capable of satisfying high speed performance demands, as demonstrated by the $300 \mathrm{kmph}$ TGV routes in France.

Over its lifetime, ballasted track may undergo up to 10 maintenance tamps until it eventually requires replacement, typically after perhaps 30 years of use. Maintenance tamping and renewal must take place within ever decreasing time slots: currently, night time possessions may provide working time windows of as little as 4 hours. Longer possessions may be possible with diversions and replacement bus services, but these are more expensive and disruptive to passengers. Ballasted track maintenance is in any case costly: for example, in 2012/13 Network Rail (UK) spent $£ 3.8$ billion or $42 \%$ of its operating budget on track maintenance and renewal ${ }^{4}$. Thus there are major advantages to be gained, in terms of reducing both operational costs and service disruption, from extending the maintenance intervals for ballasted track and its overall lifetime before renewal is required.

\section{Background}

After some initial experimentation, the basic form of the ballasted rail track structure has remained substantially the same for over 100 years. Sleepers were probably first used in large numbers on the Liverpool and Manchester Railway in the $\mathrm{UK}^{5}$. Initially all sleepers were single (mono) blocks, made of timber. Plastic and steel sleepers are now sometimes used, and in some administrations (notably France) twin-block sleepers comprising two separate blocks (one below each rail) joined by a steel bar are popular. However, on major railway lines in the developed world, sleepers are now most likely to be mono-blocks made of reinforced concrete.

Sleepers rest on ballast, which provides a free draining layer usually at least $300 \mathrm{~mm}$ deep and transfers the applied loads to the subgrade as stresses of acceptable magnitude. Ballast typically consists of grains of $20 \mathrm{~mm}$ to $65 \mathrm{~mm}$ in size (diameter). Owing to these large grain sizes, ballast supports a typical mono-block sleeper on relatively few (100 to 200) contact points ${ }^{6-8}$. This results in very high grain to sleeper contact stresses that cause abrasion and sometimes fracture, potentially increasing the quantity of fine 
materials and leading to ballast fouling with service (trafficking). Eventually the geometry along a length of track deteriorates to an unacceptable level as a result of the development of differential permanent settlement in both the ballast layer and the subgrade beneath, so that maintenance is required to restore the track geometry to give an acceptable quality for line, level and ride comfort. Maintenance is usually carried out by tamping. However, the process of tamping is itself considered to be a major cause of ballast breakage ${ }^{9}$, degradation and fines production. Thus each tamping cycle brings a diminishing return, in that the amount of trafficking that can take place before tamping is required again gradually reduces ${ }^{9}$. Eventually tamping becomes uneconomic and the track needs a complete or partial renewal.

Track quality (or maintenance need) is generally assessed by running specially instrumented trains over the track with accelerometers mounted on the axles. The acceleration data can be processed (by double integration and filtering) to evaluate differential train-loaded track geometry. The deviation from design geometry or the quality of the track is typically quantified as a standard deviation over a selected length of track. ${ }^{10}$ Higher standard deviations are indicative of poorer quality track. The tolerances for geometry variation are reduced as the line speed is increased.

Train mounted accelerometer based geometry measurement systems are unable to determine absolute settlement. However, while track settlement and standard deviation are different parameters, they are often treated interchangeably and either may be used as an indication of geometry deterioration ${ }^{9}$. This is because increased susceptibility to settlement is generally held to be indicative of a greater tendency for differential settlement.

Linear or exponential relationships such as Equation 1 are commonly used to predict the development of geometry standard deviation $(\sigma)$ with cumulative tonnes of traffic $(t)$ for specified lengths of track.

$$
\sigma=\text { A. } \exp \left(\text { a. } \mathrm{t}^{b}\right)
$$

Equation 1

where $\mathrm{A}$, $\mathrm{a}$ and $\mathrm{b}$ are determined empirically.

The coefficient A may be formed of several components and can be modified to take account of changes in ballast condition following tamping and to allow for site specific data on historical rates of deterioration. The parameters a and b are tuned so that the equation gives a representation of historic average performance for a particular section 
of track. This is essentially a curve fitting exercise, and the utility of the approach for predictive purposes relies on the availability of relevant historical data.

Until relatively recently (e.g. the late 1980s in the UK) specifications for railway ballast have generally focused on the grain size distribution and mineralogy has not been a direct concern. Owing to its relative ease of extraction a major proportion of the ballast used on the UK Network has historically been limestone. However, it has become clear that, as a result of their greater strength, igneous rocks perform better as railway ballasts ${ }^{11}$.

For at least the last 35 years, railway authorities around the world have favoured ballast gradings of relatively uniform grain size ${ }^{12-16}$. This arose at least in part from the historical need for the ballast to continue to drain even after a substantial volume of fine material had invaded or fouled the void space. However, ballast must also provide a stable and relatively stiff support for the track, for which a wider- or well-graded range of grain sizes are normally better ${ }^{17}$. To satisfy these opposing needs, ballast grading tends to be a compromise between uniformly and well/broadly graded aggregates. Railway ballast specifications worldwide generally prescribe a grain size distribution with a uniformity coefficient $\left(\mathrm{C}_{\mathrm{u}}\right)$ of between 1 and less than 3 where $\mathrm{C}_{\mathrm{u}}$ is defined as

$$
C_{u}=\frac{D_{60}}{D_{10}}
$$

Equation 2

and $D_{60}$ and $D_{10}$ are the grain sizes than which $60 \%$ and $10 \%$ respectively of the sample (by mass) is finer.

Recent studies have recommended more broadly graded ballasts in at least three different countries: Australia ${ }^{18}$ and Norway ${ }^{19}$, based on triaxial tests, and the USA ${ }^{20}$, using a discrete element modelling (DEM) approach. However, railway authorities are rather conservative when it comes to changing established practice, and only the first of these has resulted in changes to standards for operational railways ${ }^{21}$.

It is hypothesized that if the ballast grading is broader, the ballast exhibits greater stiffness and reduced plastic settlement owing to

1. a larger number of more stable contacts between the sleeper and the ballast, and a greater total contact area.

2. the packing of the ballast grains into a denser structure which is more capable of transferring stresses evenly from the sleeper through to the subgrade. 
The grading must not be so wide that the aggregate loses internal mechanical stability, which could lead (for example) to the gradual migration of grains that are too fine down to the bottom of the ballast bed (a process known as "ravelling"). This was achieved by ensuring that the ratio $\mathrm{D}_{90} / \mathrm{D}_{10}$ was less than $6 .^{22}$

In developed countries, there is now considerable scope to optimise the ballast grading for structural performance because the two main sources of fouling (train derived debris such as coal dust from open wagons, and a subgrade in direct contact with the ballast) have been substantially reduced if not entirely eliminated. Wagons carrying aggregates are generally closed or covered, while mechanisms of trackbed fouling such as ballast pumping from a soft clay subgrade are better understood and can be controlled by providing sufficient trackbed drainage and appropriate use of geotextiles and/or sand blankets in problem locations ${ }^{23,24}$. The generation of fines by in situ degradation of the ballast can be substantially reduced by the adoption of a stronger mineral aggregate (e.g. granite rather than limestone).

Optimisation of the ballast bed might involve differently graded layers. Box tests on two-layered ballast systems were carried out by Anderson and Key ${ }^{25}$ primarily in relation to maintenance by stone blowing, which leads to a finer layer of 10 to $20 \mathrm{~mm}$ grains beneath the railseats. Claisse et $\mathrm{al}^{26}$ and Claisse and Calla ${ }^{27}$ investigated the possibility of placing finer sized grains in the crib to act as a reservoir of finer stones that would naturally fall into and prevent the development of sub-sleeper voids (hanging sleepers) with trafficking. The finer grains must be coarse enough to ensure internal mechanical stability and not to affect adversely the drainage properties of the ballast. A potential disadvantage is that the finer grains may be more susceptible to ballast flight due to vibration and / or air turbulence ${ }^{28-32}$.

A second consideration is the slope of the ballast shoulder away from the track, particularly on an embankment or where the ballast bed is raised above the natural ground so that the shoulder slope continues below sleeper soffit level. There appears to be no international consensus regarding the ballast shoulder slope. In Germany a slope of $1 \mathrm{~V}: 1.25 \mathrm{H}$ is recommended ${ }^{33}$. In Australia a shallower slope of $1 \mathrm{~V}: 1.5 \mathrm{H}$ is used by most railway authorities (e.g. the Country Regional Network ${ }^{34}$ ). In the USA, a slope of $1 \mathrm{~V}: 2 \mathrm{H}$ has become the norm ${ }^{14}$, as also recommended in UIC standards ${ }^{35}$. In the UK, there is no prescribed standard and space constraints mean that the ballast often stands close to its natural angle of repose with a slope of approximately $1 \mathrm{~V}: 1 \mathrm{H}$. It is hypothesised that, in circumstances where such a steep slope continues below sleeper soffit level, the lateral constraint provided by the shoulder will be reduced leaving the 
ballast susceptible to the development of lateral strain and associated vertical settlements.

All of the research on varying ballast gradings identified in the literature was based on either numerical modelling or simple laboratory element tests that focused mainly on the material behaviour and did not attempt to represent the interaction between the track and the ballast that will occur in the field. Thus, although initial results are encouraging, larger scale laboratory tests with representative geometry and loads are needed to explore the mechanisms responsible for the improved performance of differently graded ballast and/or altered shoulder geometry.

This paper describes a series of tests using the Southampton Railway Testing Facility (SRTF), a purpose-built full-size apparatus, to investigate the effect of changing the ballast grading and shoulder slope on railway track performance, primarily in terms of resilient (in-cycle) and plastic (cumulative) settlements. Cyclic tests of a plane section of track with different specifications of ballast grading and shoulder slope were carried out, with at least 3 million loading cycles of a 20 tonne equivalent (20TE) axle load being applied in each test. To gain insights into the mechanisms controlling the development of resilient and permanent settlements, corroborating measurements of ballast shoulder movements, grain breakage and longitudinal stress within the ballast bed were made.

3 million 20TE load cycles may correspond approximately to the number of loading cycles between maintenance interventions on standard ballasted railway. On a moderately busy line 3 million loading cycles might represent about 5 years use (e.g. 50 trains/day $\times 32$ axles/train $\times 1875$ days) and on a more intensively used line as little as 2 years (e.g. $\sim 100$ trains day $\times 40$ axles/ train $\times 750$ days).

\section{Methods and materials}

\section{Methods}

\section{Test preparation}

The SRTF gives a laboratory representation of a single sleeper bay of track (Figures 1 and 2). The apparatus comprises two vertical sides $5.0 \mathrm{~m}$ long and $0.65 \mathrm{~m}$ high, constructed from heavy steel sections and panels. These are fixed to a strong floor at a distance of $0.65 \mathrm{~m}$ apart, corresponding to a typical sleeper spacing. The SRTF maintains conditions as near as practicable to plane strain. Wooden panels attached to 
the inside walls of the apparatus and a double layer of plastic sheeting at each sidewall minimizes friction at the boundaries of the test section.

Rubber mats were placed at the bottom of the SRTF to represent a slightly compressible subgrade and ensure a frictional contact at the base. Further details of the apparatus are given by Le Pen $\&$ Powrie $^{36}$ and Abadi et $\mathrm{al}^{8}$. The ballast aggregates used in the tests were sourced from Cliffe Hill quarry, Leicestershire, UK, which supplies crushed granite aggregates to a variety of industry standards for road and rail applications in the UK. In the current tests, a loading beam was used to transfer load from a single vertical hydraulic actuator onto short sections of 60EI/UIC60 rail $^{37}$ (Figure 1).

\section{[Insert Figures 1a and 1b]}

Figure 1 (a) Schematic view (b) photograph of the SRTF laboratory tests

[Insert Figure 2]

Figure 2: Cross-section through a typical test set-up

The experimental procedures followed for all of the tests reported in this paper were as follows.

1. The ballast was placed to the full width and $300 \mathrm{~mm}$ depth, up to the level of the sleeper base, and compacted by a total of 22 passes of a $22 \mathrm{~kg}, 400 \mathrm{~mm} \times 320 \mathrm{~mm}$ plate vibrator with a $5 \mathrm{kN}$ compactive force. The surface was levelled at the same time.

2. The sleeper was placed on top of the prepared ballast bed. The crib and shoulder ballast were then placed to the same level as the sleeper surface, with shoulder slopes away from the track as indicated in Figure 2. The linear variable differential transformers (LVDTs) used to measure deflection were installed.

3. The loading beam was placed across the railheads and aligned with the connection to the hydraulic actuator.

4. The load was increased once, monotonically, to $98.1 \mathrm{kN}$ at a slow rate $(5 \mathrm{kN} / \mathrm{s})$ to bed the sleeper in, provide a reproducible datum for the measurement of settlement and establish a stable load path for subsequent $3 \mathrm{~Hz}$ cyclic loading. The initial load was held for a short duration then subsequently reduced to a minimum load of $5 \mathrm{kN}$. The application and removal of this pseudo-static load was considered as the first loading cycle for subsequent calculations.

5. Cyclic loading was then applied using a sinusoidal load form at $3 \mathrm{~Hz}$, between $5 \mathrm{kN}$ and $98.1 \mathrm{kN}$. (Loading was assumed to be quasi static, and the frequency of loading was not intended to represent any particular train speed). 
6. At the end of each test all materials, including the ballast, were removed from the SRTF apparatus and replaced with new materials for subsequent tests, to ensure repeatability of the initial conditions.

\section{Justification of key testing arrangements}

The percentage of the total axle load being transferred to an individual sleeper depends on the properties of the rail, sleeper spacing, and sleeper support stiffness. An estimate of the load on an individual sleeper can be made using the beam on an elastic foundation (BOEF) model ${ }^{38}$. Calculations using the BOEF model, previous published work and recommendations by railway authorities (e.g. Standards Australia ${ }^{39}$, Network Rail $^{40}$ ) show that the transfer of $50 \%$ of the total load to a sleeper immediately below an axle is a reasonable assumption in the static case. The vertical load of 10 tonnes or $98.1 \mathrm{kN}$ applied in these tests therefore corresponded to a train having a 20 tonne axle load. This is higher than most UK passenger trains (which typically have an axle load of 10 to 15 tonnes) but less than the maximum permitted freight axle load of 25 tonnes.

$12 \mathrm{~mm}$ of rubber matting was placed at the bottom of the apparatus, below the ballast bed. The purpose of the rubber matting was to model a uniform, slightly compressible subgrade in a way that would not obscure the results of the experiments in terms of ballast settlements. In other words, the tests reported in this paper focussed on the performance of the ballast bed alone. The thickness of the rubber mat was selected so that the total resilient movement in the baseline test was representative of well performing track in the UK, in giving a vertical deflection of approximately $0.5 \mathrm{~mm}^{41}$, with the majority of this movement attributable to the rubber matting.

\section{Instrumentation}

Vertical LVDTs were placed at the four corners of the sleeper and in the middle of each long edge. A horizontal LVDT placed at the sleeper end showed that no significant lateral movement occurred in any of the tests. Figure 3 shows the LVDT locations and the areas ascribed to each for determining area-weighted average settlements in the interpretation of the results.

\section{[Insert Figure 3]}

Figure 3: LVDT locations on the sleeper to analyse permanent settlement by the area weighted method

The vertical LVDT measurements were processed to determine:

- $\quad$ permanent settlement - a single area-weighted average value representative of the whole sleeper 
- resilient deflection within cycles - including the deflected shape of the sleeper and the evaluation of any hogging or sagging

- $\quad$ spring stiffness - evaluated using both the area weighted average deflection and the average deflection at each sleeper end.

Measurements were recorded using a data logger at a frequency of $100 \mathrm{~Hz}$.

Further measurements to evaluate the mechanisms controlling the observed loaddeflection response of the sleeper were made as follows:

- Photographs of the ballast shoulder were taken at key stages of the test to evaluate ballast shoulder movement. Figure 4 shows the camera set-up used.

\section{[Insert Figure 4]}

Figure 4: Camera set-up for investigating ballast movement at a shoulder slope

Initially, a development of the digital image analysis technique described by White et $\mathrm{al}^{42}$ and Bhandari et $\mathrm{al}^{43}$ was used in an attempt to measure the downslope displacement of the ballast shoulder surface. However, the large movements of individual grains rolling down the slope disrupted the texture that the method relies on for pattern recognition, and also meant that measurement of the magnitude of movements at specific locations on the slope (which varies widely and randomly) somewhat meaningless. Thus an approach in which differences in overall pattern were quantified using a greyscale was adopted instead.

- The degree of ballast grain breakage at the sleeper base to ballast interface after completion of the cyclic loading stage was investigated by a visual survey and weighing of individual ballast grains.

- The visual survey involved counting the number of broken grains after the test was completed, and only detects breakages that can clearly be seen by eye (Figure 5). The degree of grain breakage was not sufficiently significant to detect by comparing PSDs before and after the test.

[Insert Figures 5a, 5b]

Figure 5: Typical ballast grain breakage identified by visual observation (post-test views)

- Fifty randomly-selected ballast grains retained on a $31.5 \mathrm{~mm}$ sieve were painted weighed and spread directly underneath the sleeper during the preparation of each test (Figure 6). These were recovered and weighed after testing, to determine mass loss through attrition, contact point crushing or 
other minor damage not visible to the naked eye. The weighed grains represent $25 \%$ to $50 \%$ of the typically $100-200$ in contact with the underside of the sleeper and most prone to breakage and attrition through traffic loading.

\section{[Insert Figures 6a, 6b]}

Figure 6: Fifty selected ballast grains spread directly underneath sleeper soffit a) before and b) after the test

- In each test, four pressure plates were placed along the inside wall on one side of the SRTF apparatus, to measure the development of horizontal stress within the ballast in the direction along the track. The pressure plates (Figure 7) comprised $12 \mathrm{~mm}$ thick steel plates supported by four, $10 \mathrm{~mm}$ thick load cells giving a total thickness similar to that of the $25 \mathrm{~mm}$ thick wooden panels attached to the rest of the side walls of the apparatus. The top of each plate was set level with the sleeper soffit (300 $\mathrm{mm}$ above the base of the apparatus).

$$
\text { [Insert Figures 7a, 7b] }
$$

Figure 7: Pressure plate locations in the SRTF and load cells arrangement on each plate

Measurements from each load cell were recorded using the same data logger and at the same frequency as the LVDTs.

\section{Tests carried out}

The tests reported in this paper are summarised in Table 1 . All were carried out on a G44 concrete mono-block sleeper of the type commonly used in the UK. The sleeper has major dimensions $0.285 \mathrm{~m}$ (width) $\times 0.200 \mathrm{~m}$ (height) $\times 2.500 \mathrm{~m}$ (length), a soffit area of $0.7125 \mathrm{~m}^{2}$ and a mass of $310 \mathrm{~kg}$. 
Table 1: Details of tests carried out

\begin{tabular}{|c|c|c|c|c|}
\hline $\begin{array}{c}\text { Test label } \\
\text { (for graphs) }\end{array}$ & Sleeper type & $\begin{array}{c}\text { Ballast } \\
\text { grading }\end{array}$ & $\begin{array}{c}\text { Shoulder } \\
\text { slope }\end{array}$ & $\begin{array}{c}\text { Total load } \\
\text { cycles applied } \\
\text { (millions) }\end{array}$ \\
\hline Baseline & Mono-block G44 & NR & $1: 1$ & 3.0 \\
\hline Variant 1 & Mono-block G44 & Variant 1 & $1: 1$ & 3.0 \\
\hline Variant 2 & Mono-block G44 & Variant 2 & $1: 1$ & 3.0 \\
\hline Variant 3 & Mono-block G44 & Variant 3 & $1: 1$ & 5.0 \\
\hline TLB & Mono-block G44 & TLB & $1: 1$ & 4.0 \\
\hline RPS & Mono-block G44 & RPS & $1: 2$ & 3.5 \\
\hline
\end{tabular}

\section{Materials - ballast}

Three variant ballast gradings were tested. These were designed by adding progressively greater proportions of finer grains to the standard Network Rail grading to create more broadly graded ballasts. Figure 8 shows the grain size distributions. While less uniformly graded than the Network Rail standard, all three variants lie within the ranges permitted by some other railway administrations including AREMA 24 (USA), RailCorp (Australia) and Canadian National Railway, although not necessary for main line use.

\section{[Insert Figure 8]}

Figure 8: PSD of variant gradings compared to NR grading

The minimum and maximum density of each ballast grading was measured for dense and loose specimens within a cubic, $300 \mathrm{~mm}$ sided box. Dense specimens were placed in layers, with each layer being vibrated after placement by mounting the box onto the base of a heavy duty sieve shaker. After vibration of the last layer placed, further ballast grains were added manually to obtain a level surface. Loose specimens were obtained by placing ballast gently into the box without allowing grains to fall from any height. The uniformity coefficient, selected \% passing grain dimensions $\left(\mathrm{D}_{\%}\right)$, and the maximum and minimum densities achieved are summarised in Table 2 for each grading. In all tests, the ballast was placed at or close to the maximum achievable density (a relative density index, $\mathrm{I}_{\mathrm{D}}$ of $\approx 1$ ). 
Table 2: key details of ballast gradings

\begin{tabular}{|l|c|c|c|c|c|c|c|c|}
\hline \multirow{2}{*}{ Grading } & \multicolumn{7}{|c|}{ Grain size $(\mathrm{mm})$} & \multicolumn{2}{c|}{ Density $\left(\mathrm{kg} / \mathrm{m}^{3}\right)$} \\
\cline { 2 - 9 } & $\mathrm{D}_{10}$ & $\mathrm{D}_{50}$ & $\mathrm{D}_{70}$ & $\mathrm{D}_{90}$ & $\mathrm{D}_{100}$ & $\mathrm{C}_{\mathrm{u}}$ & Loose & Dense \\
\hline \hline NR & 28 & 38 & 43 & 49 & 63 & 1.45 & 1,418 & 1,625 \\
\hline Variant 1 & 20 & 34 & 42 & 48 & 63 & 1.93 & 1,453 & 1,672 \\
\hline Variant 2 & 15 & 33 & 41 & 49 & 63 & 2.52 & 1,517 & 1,681 \\
\hline Variant 3 & 15 & 27 & 24 & 48 & 63 & 1.94 & 1,512 & 1,744 \\
\hline $10 / 20$ & 12 & 16 & 18 & 21 & 23 & 1.38 & 1,432 & 1,608 \\
\hline
\end{tabular}

In addition to the single layer variant gradings, a two-layered ballast bed (TLB) and a single layer of standard NR ballast with a re-profiled shoulder (RPS) slope were tested. Details of these tests were as follows.

- The two-layered ballast comprised a $250 \mathrm{~mm}$ layer of standard grade ballast overlain by a $50 \mathrm{~mm}$ layer of 10/20 aggregate, the size range used for stone blowing. The median PSDs for the standard NR and 10/20 gradings are shown in Figure 9.

- In the RPS test, the shoulder was placed at a $1 \mathrm{~V}: 2 \mathrm{H}$ slope away from the track (Figure 2 with $X=2$ ). In all other tests, the shoulder slope used was at the natural angle of repose of the ballast (approximately $1 \mathrm{~V}: 1 \mathrm{H}$ or $\mathrm{X}=1$ on Figure 2).

\section{[Insert Figure 9]}

Figure 9: PSD graph for standard ballast and 10/20 gradings

\section{Results and discussion}

In the presentation and discussion of results, the following definitions are used.

Permanent settlement: the irrecoverable vertical movement at the minimum load $(5 \mathrm{kN})$.

Resilient deflection: the range of movement within a single cycle associated with reducing the load from its maximum to its minimum value.

Spring stiffness: while there is a variety of definitions in the literature, the definition used in this paper is consistent with the "dynamic sleeper support stiffness" used by Network Rail, calculated as the change in vertical load per rail divided by the resilient deflection. It has units of $\mathrm{kN} / \mathrm{mm}$ and may be calculated using either a single, 
characteristic value representing the deflection of the whole sleeper, or the deflection at a specific location on the sleeper.

\section{Permanent settlement}

To obtain a single characteristic value of settlement for the whole sleeper, LVDT measurements were averaged using an area weighted method, as illustrated in Figure 3. Figure 10 shows the permanent settlement thereby calculated against the number of loading cycles on a logarithmic scale for all six tests. In these graphs, zero on the y-axis corresponds to the sleeper level (a) before the first quasi-static cycle of load was applied, and (b) after 10 loading cycles.

\section{[Insert Figures 10a and 10b]}

Figure 10: Permanent settlement zeroed (a) before the first cycle (b) after 10 cycles

Figure 10a shows that there is a significant variation in the magnitude of settlement over the initial loading cycle, as indicated by the different settlements in each test at the end of cycle 1 . These variations can be explained as a result of the particulate nature of ballast and the small number of ballast grains initially in contact with the sleeper soffit ${ }^{6-}$ ${ }^{8}$. To minimise the uncertainty introduced by the initial loading cycle and facilitate comparisons, the permanent settlements were zeroed after 10 loading cycles (Figure $10 \mathrm{~b})$.

The general trend observed in all tests is a reducing rate of accumulation of permanent settlement per cycle with the number of cycles, with permanent settlement increasing approximately linearly with the logarithm of the number of loading cycles. However, although an approximately linear relationship is often suggested in the literature ${ }^{44}$ the curves show several distinct phases which may be approximately joined with almost equivalent accuracy by piecemeal log linear, power or log log linear relationships. Projections for settlement corresponding to additional cycles beyond those tested are therefore more appropriately made by extending the final phase of the curves. The shapes of the lines in Figure 10 are consistent with field measurements of settlement with number of loading cycles reported by Shenton ${ }^{45}$ for sites in different parts of the world $^{45}$ (Figure 11). However, Shenton's data includes settlement of the subgrade. It is not surprising therefore that Shenton's field data are generally between 2 and 3 times the magnitude of Figure 10(a) at 1 million cycles.

[Insert Figure 11]

Figure 11: Track settlement data from around the world ${ }^{45}$ 
With the permanent settlement data zeroed after 10 loading cycles, the permanent settlement at key stages in all tests is compared with the baseline test in Table 3.

Table 3: Comparison of permanent settlement at key numbers of loading cycles

\begin{tabular}{|c|c|c|c|c|c|c|c|}
\hline \multirow[t]{3}{*}{ Test label } & \multirow{3}{*}{$\begin{array}{c}\text { Total } \\
\text { loading } \\
\text { cycles } \\
\text { applied } \\
\text { (millions) } \\
\end{array}$} & \multirow{2}{*}{\multicolumn{3}{|c|}{$\begin{array}{c}\text { Permanent settlement } \\
\text { (mm) at }\end{array}$}} & \multirow{2}{*}{\multicolumn{3}{|c|}{$\begin{array}{c}\begin{array}{c}\text { Percentage reduction of } \\
\text { permanent settlement (\%) at }\end{array} \\
\text { Loading cycles (millions) }\end{array}$}} \\
\hline & & & & & & & \\
\hline & & 1 & 2 & 3 & 1 & 2 & 3 \\
\hline Baseline & 3.0 & 4.85 & 5.40 & 5.69 & - & - & - \\
\hline Variant 1 & 3.0 & 4.91 & 5.37 & 5.68 & -1.3 & 0.6 & 0.2 \\
\hline Variant 2 & 3.0 & 4.95 & 5.44 & 5.74 & -2.1 & -0.6 & -0.9 \\
\hline Variant 3 & 5.0 & 3.49 & 3.86 & 4.12 & 28.0 & 28.6 & 27.6 \\
\hline TLB & 4.0 & 4.07 & 4.56 & 4.85 & 16.0 & 15.6 & 14.7 \\
\hline RPS & 3.5 & 3.21 & 3.46 & 3.63 & 33.7 & 35.9 & 36.2 \\
\hline
\end{tabular}

Figure 10 and Table 3 show that the accumulation of permanent settlement with number of loading cycles for ballast variants 1 and 2 was very similar to that in the baseline test, and practically identical over the latter part of the tests. This suggests that, the finer proportions of material introduced in variants 1 and 2, were not sufficient to alter significantly the granular skeleton. Subsequently, variant 3 was designed to introduce a greater proportion of finer material. Variant 3 demonstrated the potential for changes in the grading to reduce the rate of accumulation of permanent settlement significantly, with $\sim 28 \%$ less permanent settlement after 3 million loading cycles than in the baseline test.

At 3 million loading cycles, the TLB system showed 15\% less permanent settlement than that of the baseline test. However, the greatest reduction in permanent settlement (36\%) was produced by the RPS test. This is likely associated with the improved lateral support provided to the ballast below the sleeper soffit by the shallower shoulder slope. This would be consistent with previous work by Lackenby et al. ${ }^{46}$, who carried out cyclic triaxial tests on Australian Standard ballast ${ }^{47}$ and showed that increasing the lateral confining stress resulted in a significant reduction in ballast settlement.

Permanent settlement is often used as a proxy for the development of geometry loss in the field. However, there is no generally accepted direct relationship between geometry and loss along a length of track and the settlement of the ballast support layer below an 
individual sleeper. Thus the settlement in each test provides a qualitative indication rather than a quantitative measure of the susceptibility to develop geometry loss. On the basis that the need for a maintenance intervention might be indicated by settlement reaching a given value (e.g. 5 to $10 \mathrm{~mm}$ ) the scope for extending the number of loading cycles between maintenance interventions is clear.

\section{Resilient deflection}

For sleepers on freshly laid or just tamped ballast, the contact area is often idealised as being mainly bellow the railseats ${ }^{48}$. This is because track laying methods are intended to pack ballast beneath the railseats and provide the greatest support immediately beneath the rails. However, this pressure distribution may then change with loading cycles. Where ballast is not maintained a gap can develop below the ends of mono-block sleepers, giving rise to a condition known as centre binding ${ }^{48,49}$. In this case, a significant portion of the load applied to the rails is carried by the ballast contacting the central portion of the sleeper. The tendency towards centre binding is influenced by the sleeper bending stiffness ${ }^{50}$; the bending stiffness of a concrete sleeper is about 4 to 9 times greater than that of a timber sleeper. The development of centre binding may be assessed by comparing the resilient deflection measured at the middle and at the ends of the sleeper, and how the relative magnitudes vary with the number of loading cycles (Figure 12).

[Insert Figures 12a and 12b]

Figure 12: Average resilient sleeper deflection for ballast intervention tests measured at (a) the four corners (b) the centre of the sleeper

Figure 13 shows the ratios of end to middle resilient deflection as a function of loading cycles for each test.

[Insert Figure 13]

Figure 13: Ratio of resilient deflection between ends and middle sleepers in ballast intervention tests

In all tests the ratio of end to middle resilient deflection starts at or close to 1.0. However as loading continues, the resilient deflection at the sleeper ends gradually increases while at the centre it gradually reduces. This behaviour is indicative of hogging or centre binding. In the field, centre binding on mono-block sleepers may cause sleeper failure and instability of the track ${ }^{50}$. 
Several trends are apparent in Figures 12 \& 13.

- The tests on standard (baseline) ballast and grading variants 1 and 2 gave similar results. This is consistent with variants 1 and 2 containing insufficient finer material to influence the material behaviour.

- The test with the reduced profile shoulder (RPS) gave the lowest eventual ratio of sleeper end to middle resilient deflections.

- The two layer ballast (TLB) system gave resilient deflection ratios similar to the baseline test over the first million cycles, but after that point the increase in resilient deflection ratio was smaller.

- The test on ballast grading Variant 3 gave larger resilient deflection ratios than all of the other tests. This might appear to suggest a greater tendency towards centre binding, but arises more because the ballast below the middle of the sleeper middle is stiffer. Thus while the resilient deflection ratio was greater, the absolute values of resilient deflection were smaller than in the baseline test.

The sleepers used in the laboratory tests were carefully inspected after each test for signs of distress such as cracks. None were found, confirming that the hogging moments developed in these tests were well within the capacity of the sleepers.

In practice, tamping to restore the ballast structure in the vicinity of the rail seats limits or prevents the development of centre binding if carried out sufficiently frequently. A support system that enables a more uniform deflected sleeper profile to be kept for a greater number of load cycles is therefore likely to require less frequent maintenance. In this respect, the sleeper in the test with the re-profiled ballast shoulder (RPS) performed best. Measurements presented later show that this was because lateral movement of the ballast from under the sleeper ends was prevented by the inherently more stable shoulder slope.

\section{Spring stiffness}

Figures 14a and $\mathrm{b}$ show the spring stiffnesses (defined at the start of this Section) evaluated using the dynamic load applied and (a) the average of the deflections measured at the sleeper corners only, and (b) the average of all measured deflections (middle and corners), calculated using the area weighted method, with the weightings indicated in Figure 3.

[Insert Figures 14a and 14b] 
Figure 14: Spring stiffnesses for ballast intervention tests based on average deflections measured (a) at the four corners (b) over the whole sleeper (area weighted method)

As it is related to the inverse of the resilient deflection, the spring stiffness determined at the sleeper ends reduces with increasing number of cycles, which is consistent with the gradual development of a hogged sleeper shape. The area weighted method results are more uniform because as the sleeper became centre-bound and hogged the deflection in the middle reduced, compensating for the increased deflection at the sleeper ends. Figure 13b shows a trend of increasing area weighted spring stiffness with the number of loading cycles in all tests.

A link between the variation in the per sleeper global spring stiffness along the track and the rate of track geometry degradation has been postulated ${ }^{51,52}$. While this seems intuitively plausible in that a greater variation in spring stiffness between sleepers will lead to an increased variation in dynamic loads hence differential settlement, there are limited publicly-available field data to confirm it. One of the few published papers ${ }^{53}$ to include field data demonstrated that any such relationship that could be identified was at best subjective.

To investigate the influence of the support stiffness on the accumulation of plastic settlement of an individual sleeper in these laboratory tests, the permanent settlement is plotted against spring stiffness (both at 3 million cycles) in Figure 15. Figure 15 appears to show that a higher spring stiffness is associated with a smaller permanent settlement. This is perhaps indicative of denser ballast gradations having less potential to compact (variant 3), and / or the beneficial effects of an improved degree of lateral confinement on both resilient and plastic settlement in the case of the RPS.

\section{[Insert Figure 15]}

Figure 15: Spring stiffness against ballast permanent settlement (re-zeroed after 10 loading cycles) after 3 million loading cycles from ballast intervention tests

\section{Shoulder movements}

The movement of ballast grains on the shoulder slope was assessed by comparing digital images of the shoulder prior to testing with images at key numbers of loading cycles. Figures 16 and 17 show ballast shoulder slope movements for variant 3 and the RPS slope respectively. These figures were produced by subtracting the contrast of the image at the start of the test from the contrast of the image at the stage of the test under 
consideration. The subtraction of identical images results in a completely black image. If grains have moved, the images are not identical and subtraction results in an image with shades of grey and white, the extent of which gives a repeatable, rigorous and quantitative indication of the overall degree of ballast grain movement.

\section{[Insert Figures 16a and 16b and 16c]}

Figure 16: Representation of ballast grain movements on the shoulder slope (a) prior to testing, (b) during harvesting the data at 0.25 million loading cycles and (c) the end of the variant 3 test

[Insert Figures 17a and 17b and 17c]

Figure 17: Representation of ballast grain movements on the shoulder slope (a) prior to testing, (b) during harvesting the data at 0.25 million loading cycles and (c) the end of the RPS test

Movement of ballast grains on the shoulder slope occurred during cyclic loading in every test. Comparison of the images shows that the RPS slope test had by a considerable margin the least white colour (Figure 16), representing the least movement of ballast grains. The next least movement was the test on ballast gradation variant 3 (Figure 15). These data confirm that the RPS slope was more effective than any of the variations in ballast grading investigated in reducing the tendency for instability of ballast grains on the shoulder slope, hence providing the most effective lateral support to the ballast below the sleeper.

\section{Grain breakage}

Ballast grain to sleeper and ballast grain to grain contact areas are very small. Thus when the ballast is loaded, high stress concentrations develop - particularly at key locations such as at the sleeper base. It is generally considered that the contact stresses cause the sharp edges and corners (asperities) of ballast grains to break off, resulting in more rounded grains and (it is argued) a reduction in the bulk strength of the material. ${ }^{54}$

A visual survey for breakage of the ballast directly under the sleeper soffit was carried out at the end of each test. Ballast breakage identified in this way is reported in Table 4, in which the tests are ordered by reducing number of broken grains. The permanent settlement in each test is also indicated. 
Table 4: Summary of ballast breakage data

\begin{tabular}{|l|c|c|c|c|}
\hline Test ID & $\begin{array}{c}\text { Total load } \\
\text { cycles applied } \\
\text { (millions) }\end{array}$ & $\begin{array}{c}\text { Number } \\
\text { of broken } \\
\text { grains }\end{array}$ & $\begin{array}{c}\text { Settlement at 3M loading } \\
\text { cycles after zeroed at 10 } \\
\text { cycles (mm) }\end{array}$ & $\begin{array}{c}\text { The average } \\
\text { loss of mass for } \\
\text { 50 grains (\%) }\end{array}$ \\
\hline \hline Baseline & 3.0 & 11 & 5.69 & Not measured \\
\hline Variant 2 & 3.0 & 8 & 5.74 & 0.18 \\
\hline Variant 1 & 3.0 & 2 & 5.68 & 0.19 \\
\hline Variant 3 & 5.0 & 2 & 4.12 & 0.29 \\
\hline TLB & 4.0 & None & 4.85 & 0.06 \\
\hline RPS & 3.5 & None & 3.63 & 0.10 \\
\hline
\end{tabular}

Broken grains occurred in most tests, with tests having lower permanent settlement showing less breakage. However, in all cases the number of broken grains was small the maximum was 11 in the baseline test. Breakage occurred mainly in larger grains at the edges of the sleeper soffit. Hardin ${ }^{55}$ observed that the potential for breakage of a soil grain increases with its size owing to the greater probability of defects being present. Ballast grains at the sleeper soffit edge are likely to experience more severe combinations of compressive and shear contact stresses than grains elsewhere in the ballast bed.

Column 5 of Table 4 shows the average loss of mass for the 50 weighed grains painted yellow and placed beneath the sleeper base (Figure 6). These grains showed no obvious signs of damage when recovered. However, when weighed there was a consistent small loss of mass. This could be caused by ballast abrasion/attrition at the contacts and/or by dust/loose surficial material falling from the ballast during loading.

\section{Longitudinal horizontal stress}

The variation with number of loading cycles of the maximum longitudinal horizontal stress in the ballast measured at pressure plates 1 and 4 (Figure 7) is shown in Figures 18 and 19. Plates 1 and 4 were selected because they give an indication of the evolution of stress beneath the sleeper end (plate 4) and near the sleeper middle (plate 1), i.e. at locations where differences are likely to be more pronounced.

\section{[Insert Figure 18]}

Figure 18: Maximum longitudinal stress Vs. loading cycles: pressure plate 1 (sleeper middle)

[Insert Figure 19] 
Figure 19: Maximum longitudinal stress Vs. loading cycles: pressure plate 4, (sleeper end)

The initial longitudinal stresses (Figures 18 and 19) show a range of magnitudes. These relate to the initial condition of ballast (as placed) and the number of ballast grains in contact with each plate.

In each test, the ballast pressure at plate 1 (in the middle section of the sleeper / centre of the track) increased with the number of loading cycles (Figure 18). An increase in longitudinal pressure at the middle section of the sleeper indicates a compaction of the ballast at the centreline of track, consistent with the ballast there attracting more load as centre binding develops. The ballast pressure in the middle section of the track settles to an almost constant value for each test. However, the constant value in any given test varies (e.g. between $15 \mathrm{kPa}$ to $32 \mathrm{kPa}$ ) and there is no clear correlation between the value of constant stress and ballast settlement. For example the longitudinal stresses adjacent to the sleeper middle associated with variants 1 and 2 are generally greater than in the baseline test, while those associated with variant 3 and in tests RPS and TLB are similar.

The ballast pressure at pressure plate 4 decreased rapidly during the initial loading cycles (Figure 19), and then more gradually with further loading cycles until it reached an almost constant value. The reduction in longitudinal stress within the ballast is consistent with a reduced vertical load and a loss of lateral confinement as the ballast moves out from under the sleeper ends allowing deflections there to increase. Although the initial magnitudes of ballast longitudinal stress at plate 4 in each test were different, it seems that the variant 3 grading and the RPS slope were successful in keeping the longitudinal pressure in the shoulder areas higher than in the other tests. This is consistent with the lower movements of grains on the ballast shoulder observed in the photographs and smaller sleeper end settlements measured in these tests.

\section{Conclusions}

1. Ballasted railway track requires periodic maintenance to restore its geometry (quality), which gradually deteriorates as a result of trafficking. Although it is the development of differential settlement that triggers the need for a maintenance intervention, it is not possible to predict this by calculation. However, proxy measures of resilient modulus (track stiffness) and the development of a given amount of permanent settlement may be used. 
2. Cyclic loading tests on mono-block sleepers have demonstrated the ability of various relatively simple modifications to the ballast bed to increase the resilient modulus and reduce the rate of accumulation of permanent settlement; and hence potentially extend the interval between maintenance interventions to restore the track vertical geometry.

3. All tests showed the development (with increasing number of load cycles) of sleeper hogging under load, a gradual increase in longitudinal horizontal stress within the ballast under the middle section of the sleeper and a gradual reduction in longitudinal stress at the sleeper ends. These behaviours are all symptomatic of the development of centre binding and a need for maintenance.

4. The introduction of a more widely graded ballast (variant 3), a two layer ballast system (TLB) and a reduced shoulder slope (RPS) showed the most potential for reducing the required frequency of maintenance interventions. Tests incorporating these ballast modifications exhibited improved behaviour in terms of

- smaller and more uniformly distributed permanent settlements

- a higher stiffness

- smaller reductions in longitudinal horizontal stress within the ballast at the sleeper end

- less movement of ballast grains on the ballast shoulder slope

- reduced ballast grain breakage

- a reduction in the rate of development of the symptoms of centre binding.

5. The test with a shallower ballast shoulder slope (RPS) showed the most significant improvement in all aspects of behaviour. Thus re-profiling steeper shoulder slopes in the existing network could be a cost effective option for obtaining longer intervals between maintenance interventions.

\section{Acknowledgments}

The authors are grateful for the financial support of the UK Engineering and Physical Sciences Research Council (EPSRC) as part of the TRACK21 project grant reference EP/H044949/1 and to Network Rail for their support in kind. All data supporting this study are openly available from the University of Southampton repository at [DOI to be inserted].

\section{References}

1. Department for Transport (DfT), Passenger km travelled from statistical data set table RAI0103 (Franchised operators only). [Online]. Available: 
https://www.gov.uk/government/statistical-data-sets/rai01-length-of-routedistance-travelled-age-of-stock\#table-rai0103, 2013, [Accessed 06/08 2013].

2. Office for National Statistics (ONS),. Gross domestic product by gross value added industry of output, 2014 [Online]. [Accessed 06/08 2014].

3. Powrie, W, On track: the future for rail infrastructure systems,. Proceeding of The Institution of Civil Engineers, Civil Engineering 167, 2014, 19-27.

4. Network Rail, Network Rail infrastructure limited regulatory: Financial statements year ended 31 ${ }^{\text {st }}$ March 2013, 2013.

5. Morgan. Industrial archaeology civil engineering: railways, London, Longman Group Limited, 1971.

6. Shenton, M. J, Deformation of railway ballast under repeated loading condition. In: KERR, A. D., ed. Railroad Track Mechanics and Technology: Proceeding of a Symposium, $21^{\text {st }}-23^{r d}$ April 1978, Princeton University, 1978.

7. Abadi, T. C., Le Pen, L. M., Zervos, A. \& Powrie, W, Measuring the contact area and pressure between the ballast and the sleeper, The International Journal of Railway Technology, Saxe-Coburg Publication, 2015, Vol 4, Issue 2, 45-72.

8. Abadi, T. C, Effect of sleeper and ballast interventions on rail track performance, Thesis of Doctor of Philosophy, Faculty of Engineering and the Environment, University of Southampton, Southampton, U.K, 2015.

9. Selig, E. T. \& Waters, J. M, Track geotechnology and substructure management, Telford American Society of Civil Engineers, Publications Sales Dept. distributor, London \& New York, T, 1994.

10. Rail Safety and Standards Board GC/RT5021, Issue 4. Railway Group Standard: Track System Requirements. 2009.

11. Clifton, A. W., Klassen, M. J. \& Watters, B. R, Production and testing of Bballast, Journal Transportation Research Record, 1987, Vol. 1131, 26-34.

12. Raymond, G. \& Diyaljee, V. A, Railroad ballast load ranking classification. Journal of the Geotechnical Engineering Division, 1979, Vol. 105, 1133-1153.

13. Canadian Pacific Rail, CP rail specifications for ballast: Evaluating processed rock, slag and gravel ballast sources. Canadian Pacific Rail, 1984.

14. AREMA, AREMA manual for railway engineering. roadway and ballast. AREMA. 2000.

15. AREMA, American railway engineering and maintenance-of-way association: Chapter 1: Roadway and ballast. Ballast, 2012.

16. British Standards Institution, BSI standard publication BS EN 13450:2013: Aggregates for railway ballast. British standards institution, 2013.

17. Raymond, G. P, Research on railroad ballast specification and evaluation, Journal Transportation Research Record, 1985b, Vol. 1006, 1-8. 
18. Indraratna, B. \& Salim, W, Mechanics of ballasted rail tracks: a geotechnical perspective, London, Taylor \& Francis, 2005.

19. Nalsund, R, Effect of grading on degradation of crushed-rock railway ballast and on permanent axial deformation, Journal of the Transportation Research Board, 2010, No. 2154, 2, 149-155.

20. Tutumluer, E., H. Huang, Y. M. A. Hashash, and J. Ghaboussi. AREMA Gradations Affecting Ballast Performance Using Discrete Element Modeling (DEM) Approach. Proc., Annual Conference of the American Railway Engineering and Maintenance-of-Way Association, Sept. 20-23, Chicago, Ill, USA, 2009

21. RailCorp engineering specification. SPC 241: Ballast. Railcorp, 2009.

22. Natural Resources Conservation Service Michigan.. National engineering handbook part 633- soil engineering. National engineering handbook. United States Department of Agriculture (USDA), 2008.

23. Chrismer, S. M. \& Richardson, G, In-track performance of geotextiles at Caldwell, Texas, Journal Transportation Research Record, 1986, Vol. 1071.

24. Lacy, H. S. \& Panne, J, Use of geosynthetics in the design of railroad tracks, Journal Transportation Research Record, 1987, Vol. 1131, 99-106.

25. Anderson, W. F. \& Key, A. J. Model testing of two-layer railway track ballast, Journal of Geotechnical and Geoenvironmental Engineering, 2000, 126, 317323.

26. Claisse, P., Keedwell, M. \& Calla, C, Tests on a two-layered ballast system, Proceeding of The Institution of Civil Engineers, Transport, 2003, 156, 93-101.

27. Claisse, P. \& Calla, C, Rail ballast: Conclusions from a historical perspective, Proceedings of the Institution of Civil Engineers Transport, 2006. 159, 69-74.

28. Kwon, H. B. \& Park, C. S, An experimental study on the relationship between ballast-flying phenomenon and strong wind under high-speed train, $7^{\text {th }}$ World Congress Railway Research, 2006, Montreal, Canada. 625.

29. Quinn, A. D., Hayward, M., Baker, C. J., Schmid, F., Priest, J. A. \& Powrie, W, A full-scale experimental and modelling study of ballast flight under high-speed trains, Proceedings of the Institution of Mechanical Engineers Part F-Journal of Rail and Rapid Transit, 2010, 224, 61-74.

30. Lazaro, B. J., Gonzalez, E., Rodriguez, M., Rodriguez, M., Osma, S. \& Iglesias, J, Characterization and modeling of flying ballast phenomena in high-speed train lines, The $9^{\text {th }}$ World Congress Railway Research. 2011, Lille.

31. Jing, G. Q., Zhou, Y. D., Lin, J. \& Zhang, J. Ballast flying mechanism and sensitivity factors analysis, International Journal on Smart Sensing and Intelligent Systems, 2012, Vol. 5, 928-938. 
32. Saussine, G, Ballast flying and projection phenomena: Issues and Challenges. William W. Hay Railroad Engineering Seminar,2013, University of Illinois.

33. Marx, L. \& Mobmann, D, DB manual work procedures for permanent way maintenance, Bahn Fachverlag, 2012.

34. Country Regional Network, Engineering standard track, CRN CS 240 Ballast 2013.

35. UIC, UIC code 719R; Earthworks and trackbed for railway lines, 2008.

36. Le Pen, L. M. \& Powrie, W, Contribution of base, crib, and shoulder ballast to the lateral sliding resistance of railway track: a geotechnical perspective, Journal of Rail and Rapid Transit, 2011, Vol. 225, 113-128.

37. British Standards Institution, Railway applications-track-rail. BS EN 13674-1: 2011 Part 1: Vignole railway rails 46 kg/m and above. London: British Standard Institution, 2011.

38. Timoshenko, S, Methods of analysis of statical and dynamical stresses in rails, Proceedings Second International Congress of Applied Mechanics, Zurich, 1927, 407-418.

39. Standards Australia, Australian standard, AS 1085.14-2003, Railway track material part 14: Prestressed concrete sleepers. Australia: Standard Australia, 2003.

40. Network Rail, Network Rail NR/SP/TRK/9039: Business process document formation treatments, 40 Melton Street, London NWI 2EE: Network Rail, 2005.

41. Bowness, D., Lock, A. C., Powrie, W., Priest, J. A. \& Richards, D. J, Monitoring the dynamic displacements of railway track, Journal of Rail and Rapid Transit, 2005, Vol. 221, 13-22.

42. White, D. J., Take, W. A. \& Bolton, M. Soil deformation measurement using particle image velocimetry (PIV) and photogrammetry. Geotechnique, Vol 53 (7), 619-631. 2003.

43. Bhandari, A. R., Powrie, W. \& Harkness, R. A digital image-based deformation measurement system for triaxial tests. Geotechnical Testing Journal, Vol. 35 (2), 209-226. 2012.

44. Dahlberg, T.. Some railroad settlement models-A critical review. Proceedings of the Institution of Mechanical Engineers, Part F: Journal of Rail and Rapid Transit, 2001, Vol. 215, 289-300.

45. Shenton, M. J. Ballast deformation and track deterioration. Track Technology. Proceedings of a conference organized by the Institution of Civil Engineers. University of Nottingham, 1984, pp.242- 252 
46. Lackenby, J., Indraratna, B., McDowell, G. \& Christie, D, Effect of confining pressure on ballast degradation and deformation under cyclic triaxial loading, Geotechnique, 2007, 57, 527-536.

47. Standards Australia, Australian standard aggregates and rock for engineering purposes; part 7: Railway ballast, Australia: Standards Australia, 1996..

48. Raymond, G. P, Design for railroad ballast and subgrade support, Journal of the Geotechnical Engineering Division, 1978, Vol. 104, 45-60.

49. Turcke, D. J. \& Raymond, G. P, Three-dimensional analysis of rail track structure, Journal Transportation Research Record, 1979, Vol. 733, 1-6.

50. Stewart, H. E, Measurement and prediction of vertical track modulus, Transportation Research Record, 1985, Vol. 1022, 65-71.

51. Hunt, G. A, EUROBALT optimises ballasted track. Railway Gazette International, 2000, 156, 813.

52. Dahlberg, T, Railway track stiffness variations-consequences and countermeasures, International Journal of Civil Engineering, 2010, Vol. 8, 1-12.

53. Sussman, T. R., Ebersohn, W. \& Selig, E. T, Fundamental nonlinear track loaddeflection behaviour for condition evaluation, Transportation Research Record, 1742, 2001, 61 - 67.

54. Marsal, R. J, Large scale testing of rockfill materials, ASCE Journal of The Soil Mechanics and Foundation Division, 1967, 93, 27-43.

55. Hardin, B. O, Crushing of soil particles, Journal of Geotechnical Engineering, 1985, Vol. 111, 1177-1192.

\section{Figures:}

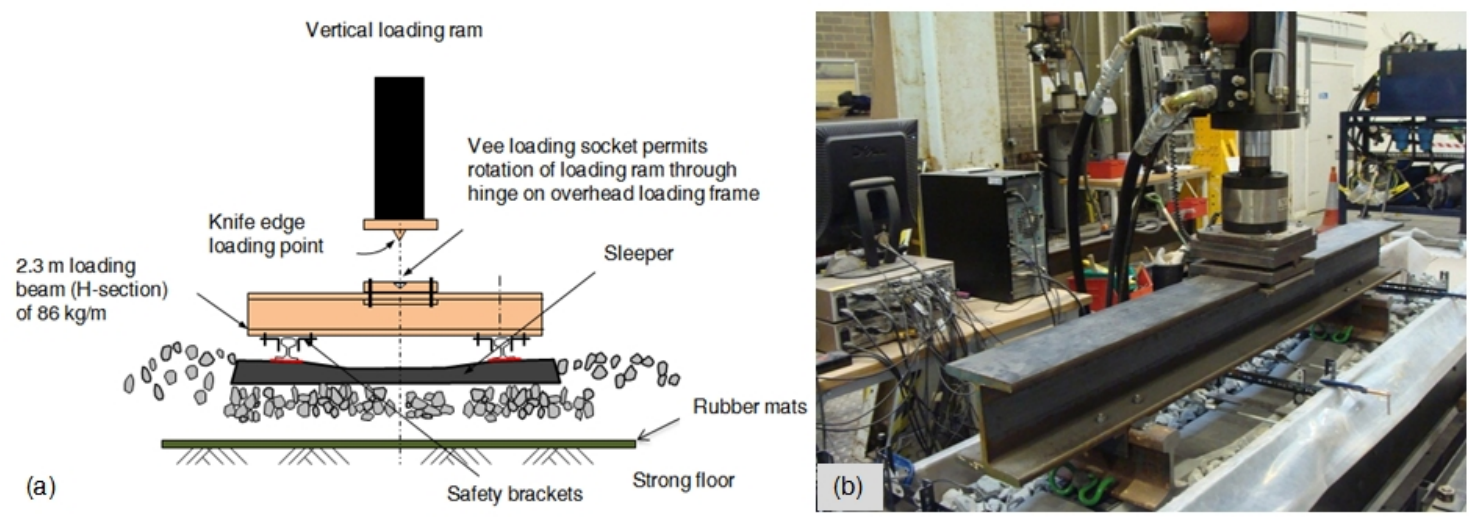

Figure 1 (a) Schematic view (b) photograph of the SRTF laboratory tests 


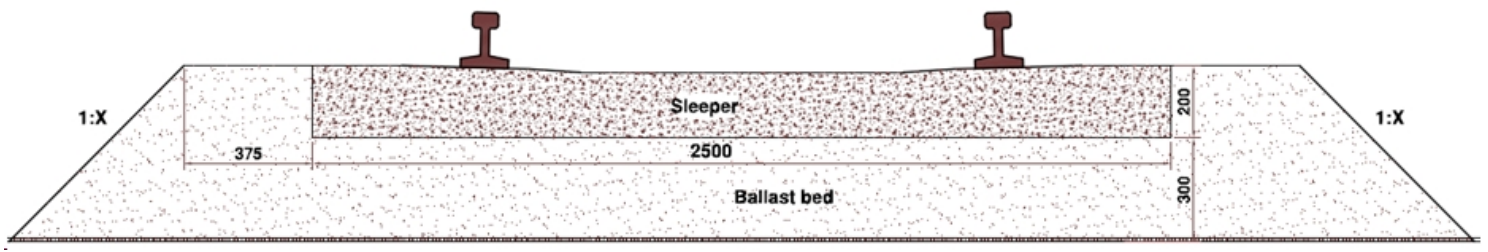

Figure 2: Cross-section through a typical test set-up

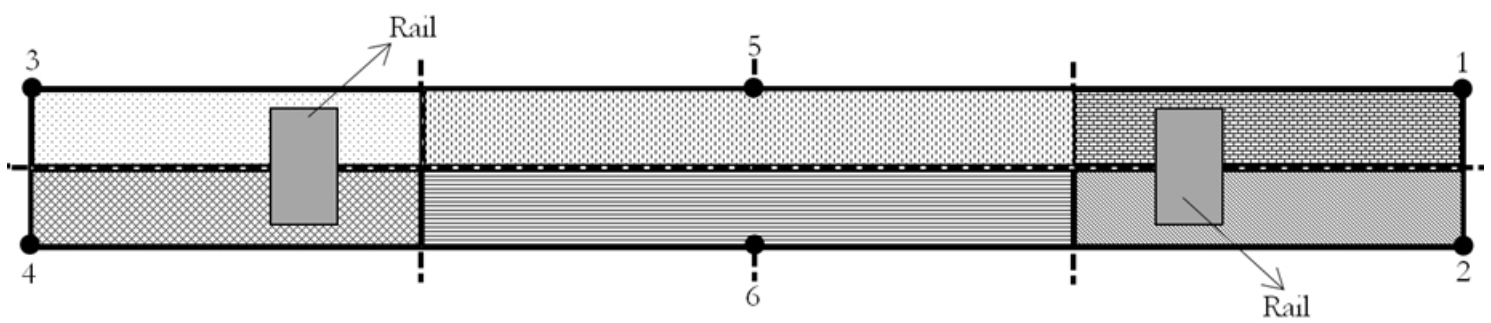

Figure 3: LVDT locations on the sleeper to analyse permanent settlement by the area weighted method

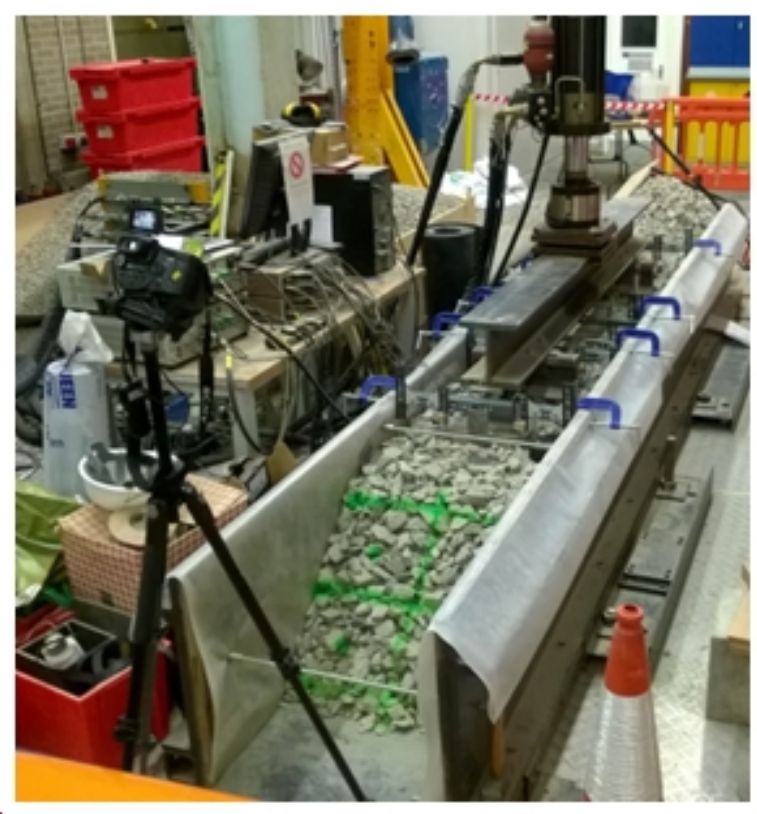

Figure 4: Camera set-up for investigating ballast movement at a shoulder slope 

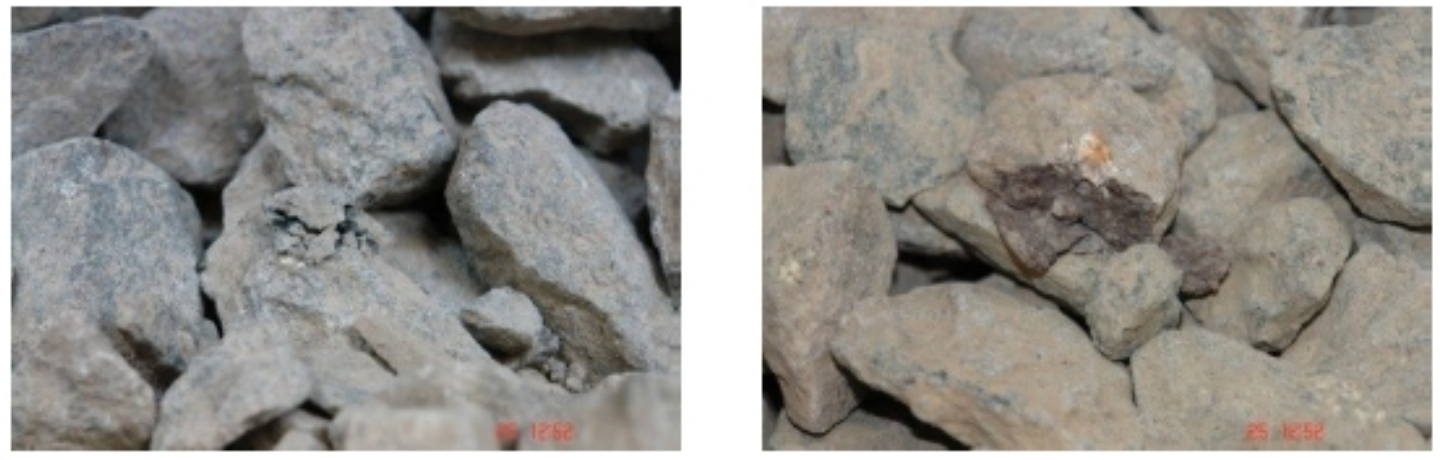

Figure 5: Typical ballast grain breakage identified by visual observation (post-test views)
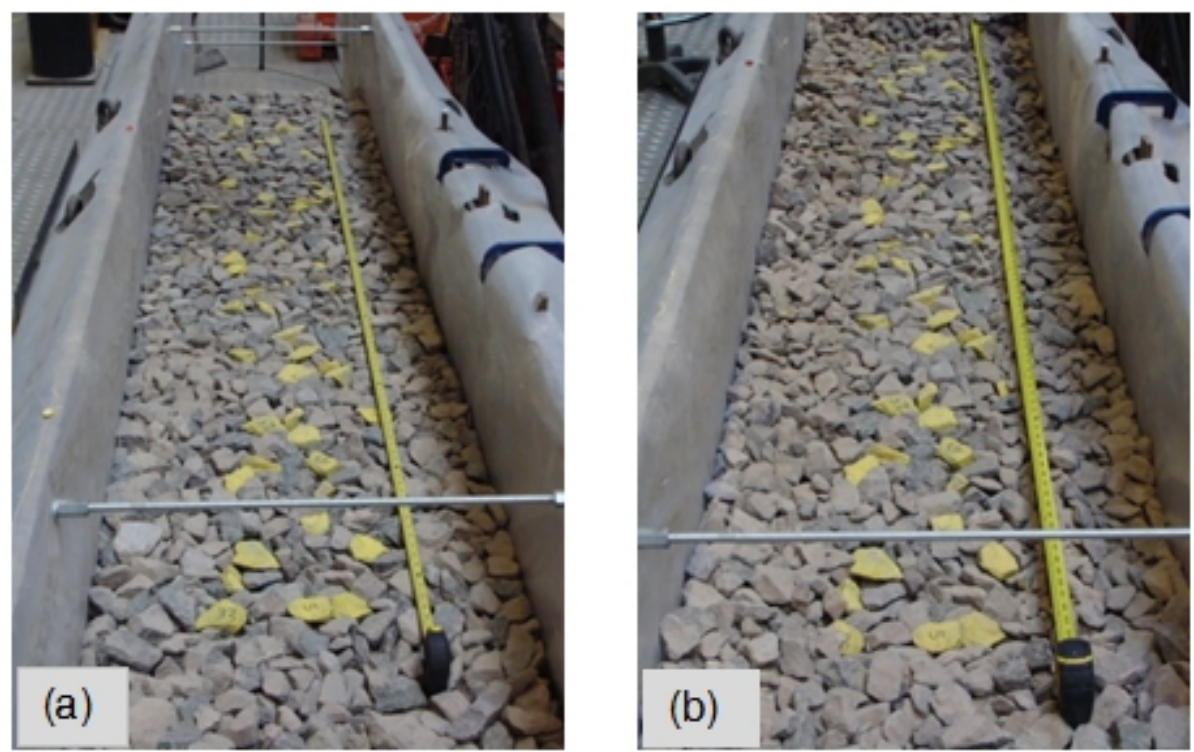

Figure 6: Fifty selected ballast grains spread directly underneath sleeper soffit a) before and b) after the test

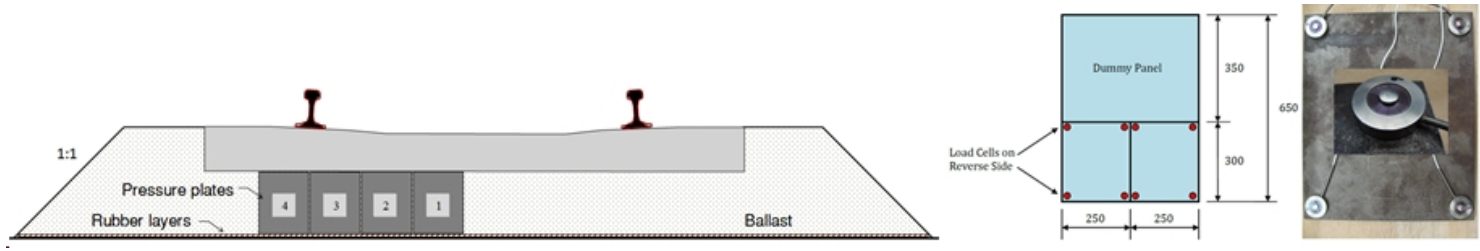

Figure 7: Pressure plate locations in the SRTF and load cells arrangement on each plate 


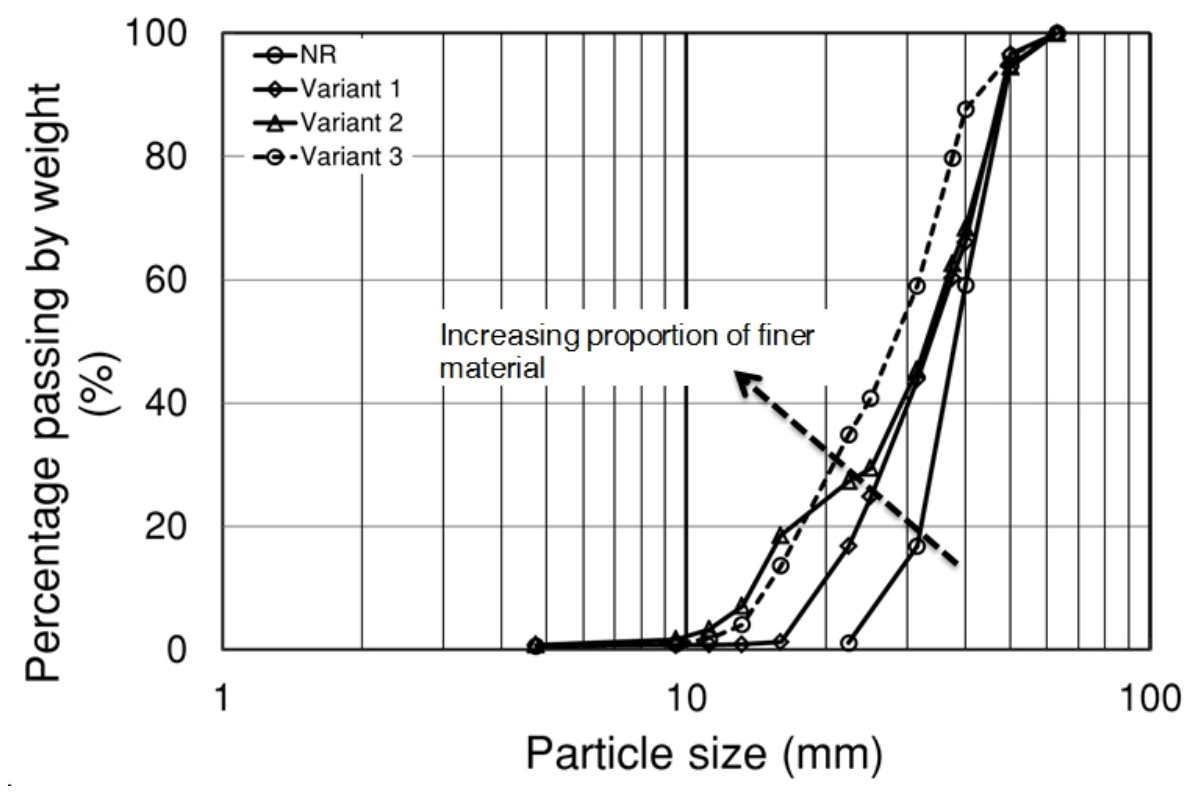

Figure 8: PSD of variant gradings compared to NR grading

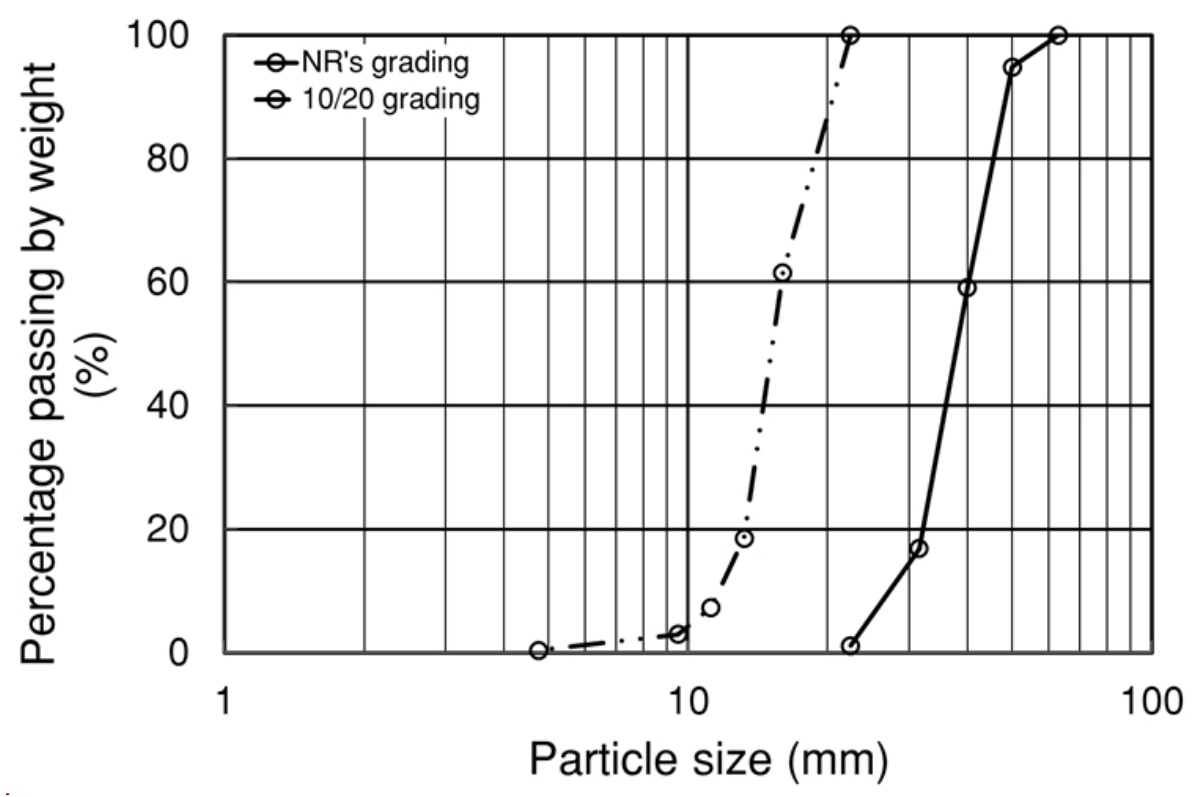

Figure 9: PSD graph for standard ballast and 10/20 gradings 

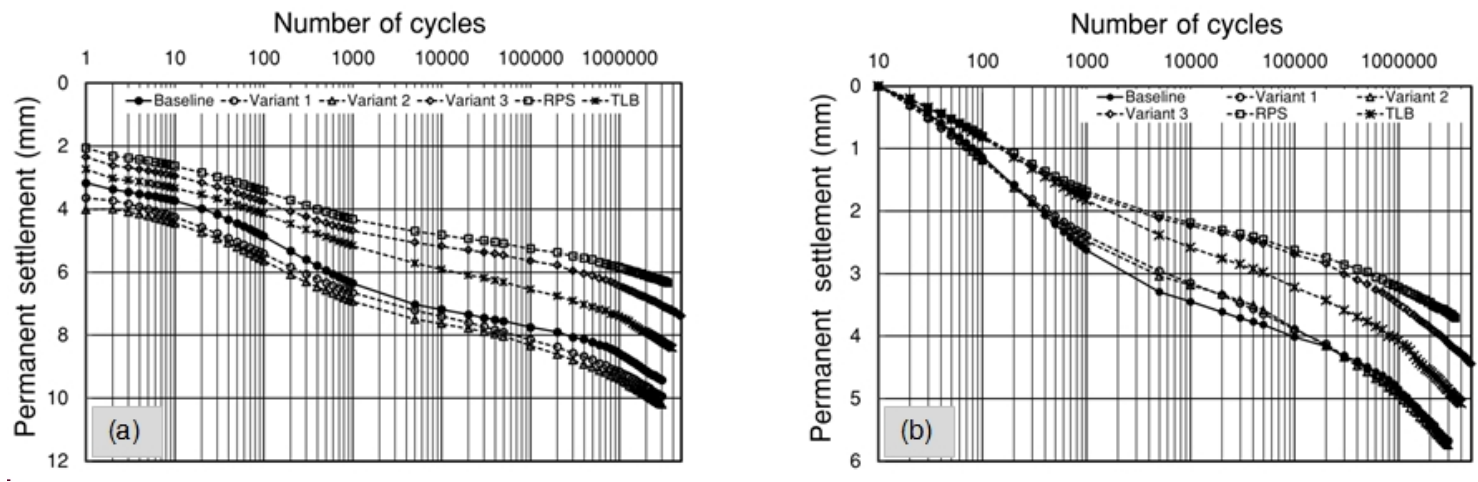

Figure 10: Permanent settlement zeroed (a) before the first cycle (b) after 10 cycles

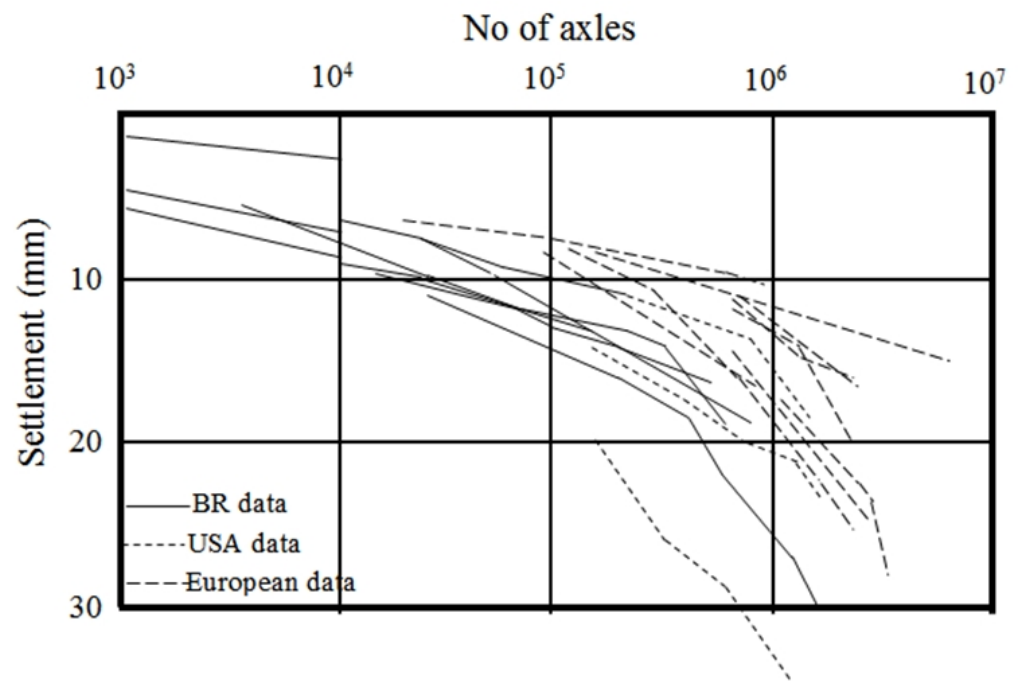

Figure 11: Track settlement data from around the world (after Shenton, 1984) 

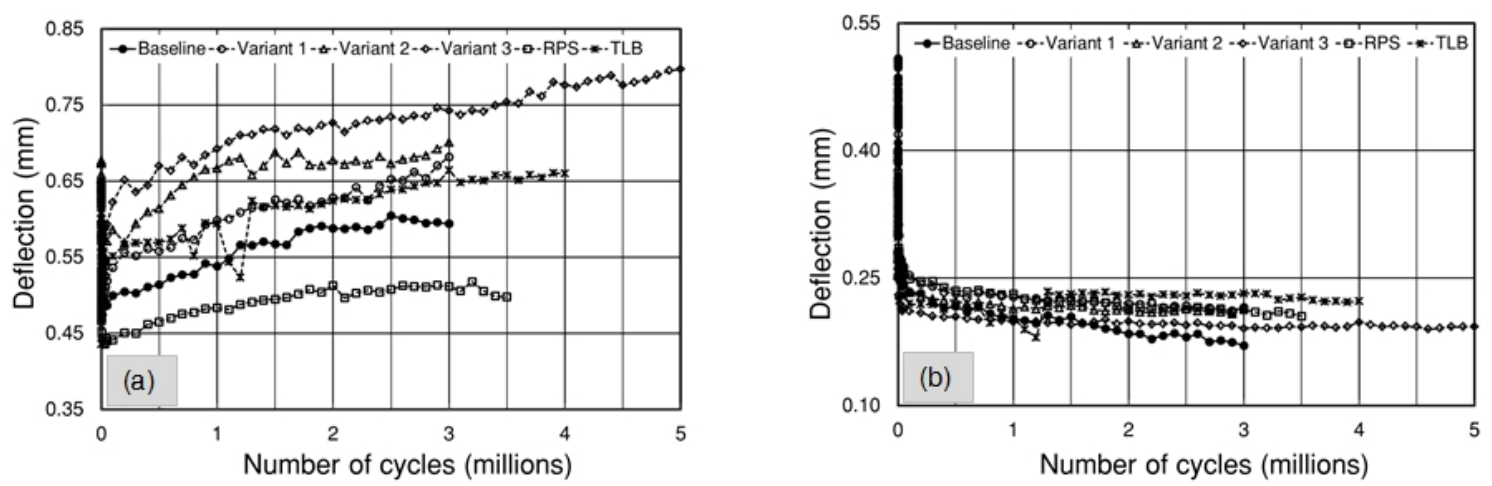

Figure 12: Average resilient sleeper deflection for ballast intervention tests measured at (a) the four corners (b) the centre of the sleeper

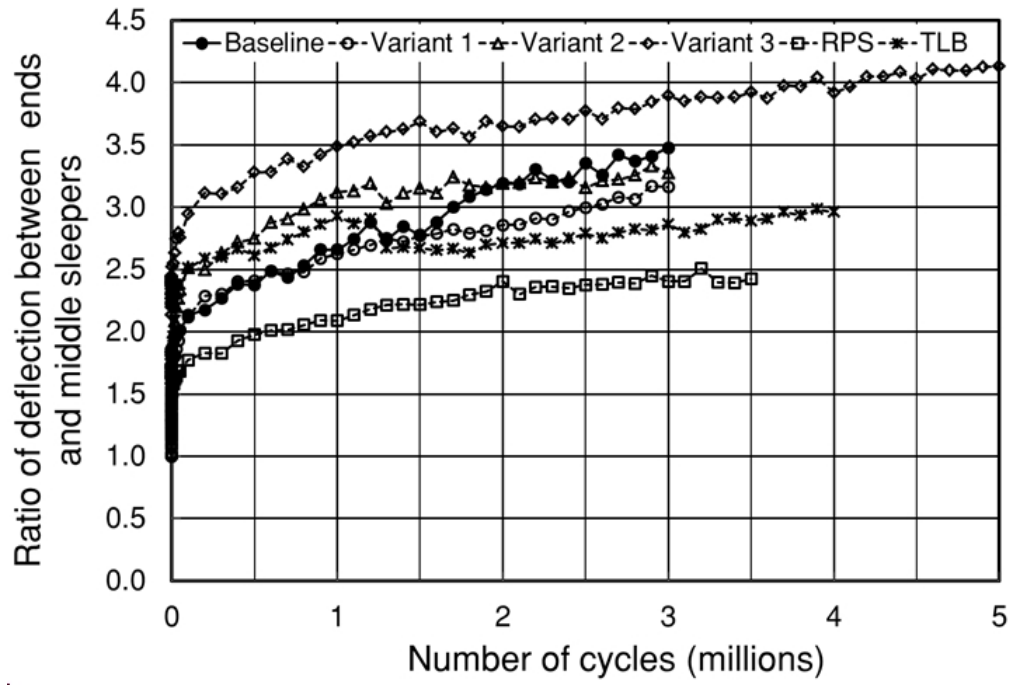

Figure 13: Ratio of resilient deflection between ends and middle sleepers in ballast intervention tests 

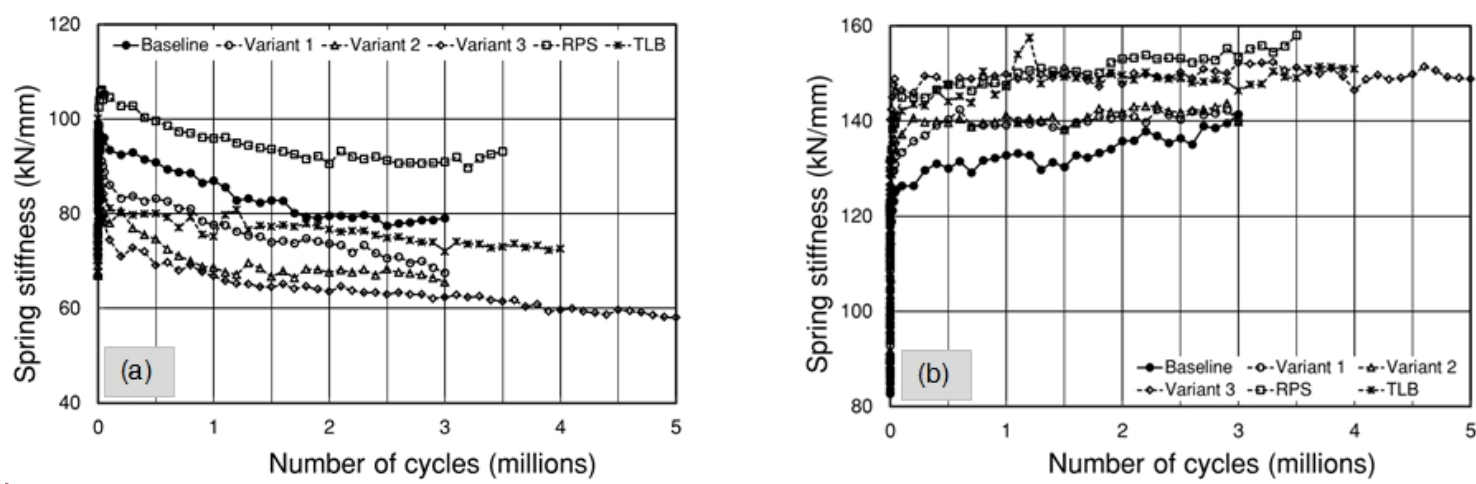

Figure 14: Spring stiffnesses for ballast intervention tests based on average deflections measured (a) at the four corners (b) over the whole sleeper (area weighted method)

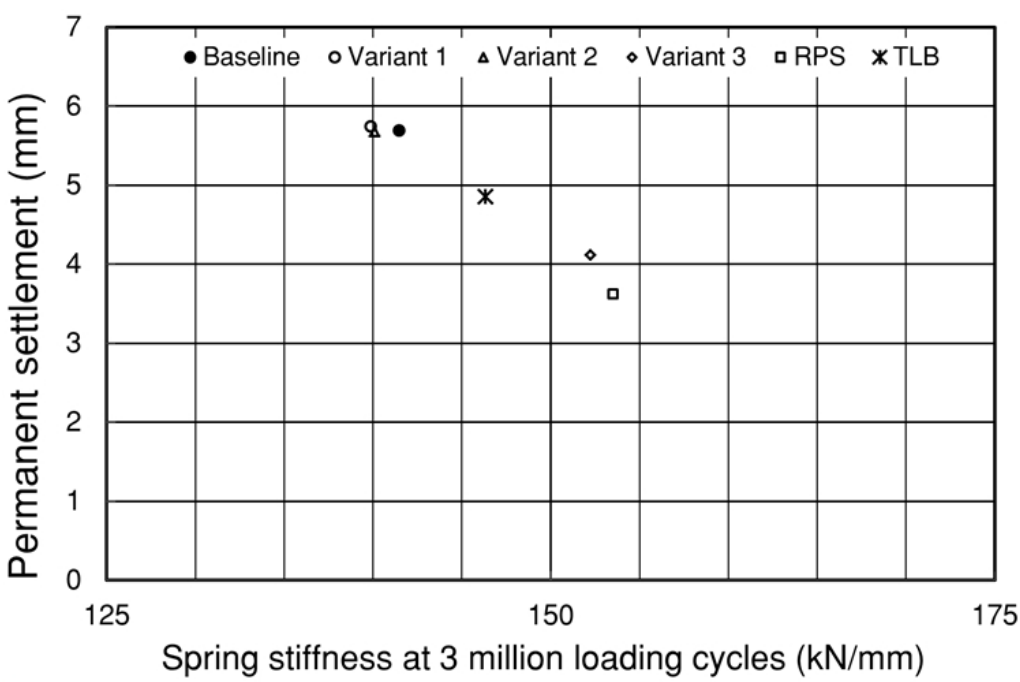

Figure 15: Spring stiffness against ballast permanent settlement (re-zeroed after 10 loading cycles) after 3 million loading cycles from ballast intervention tests 

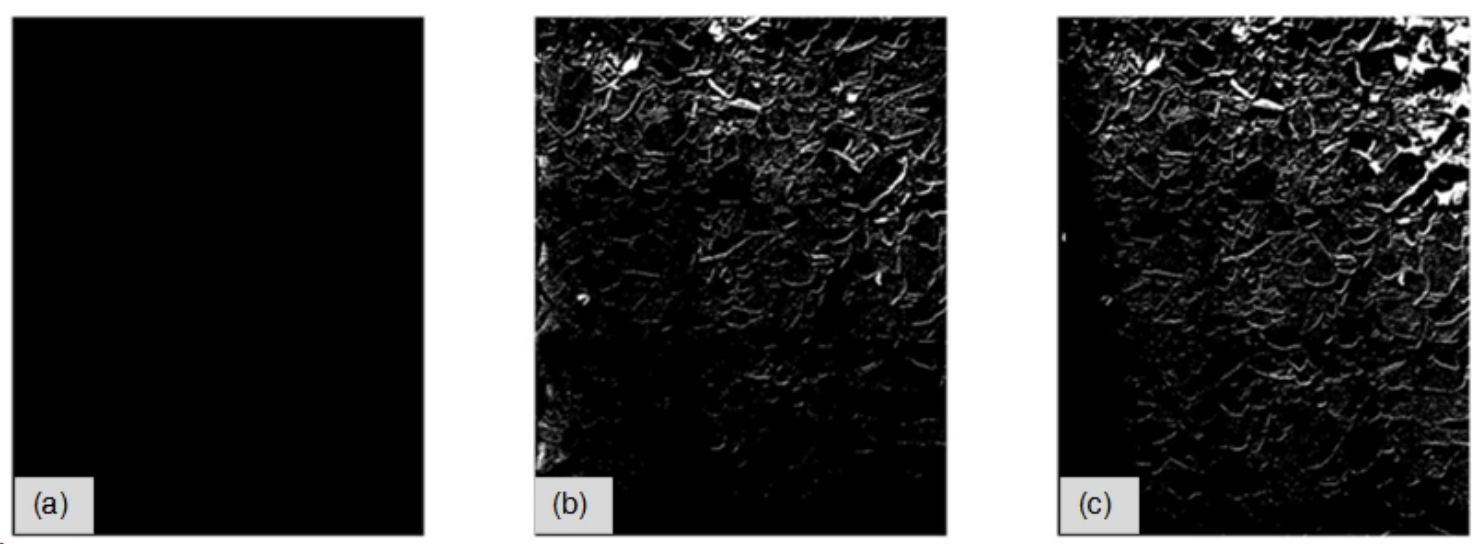

Figure 16: Representation of ballast grain movements on the shoulder slope (a) prior to testing, (b) during harvesting the data at 0.25 million loading cycles and (c) the end of the variant 3 test
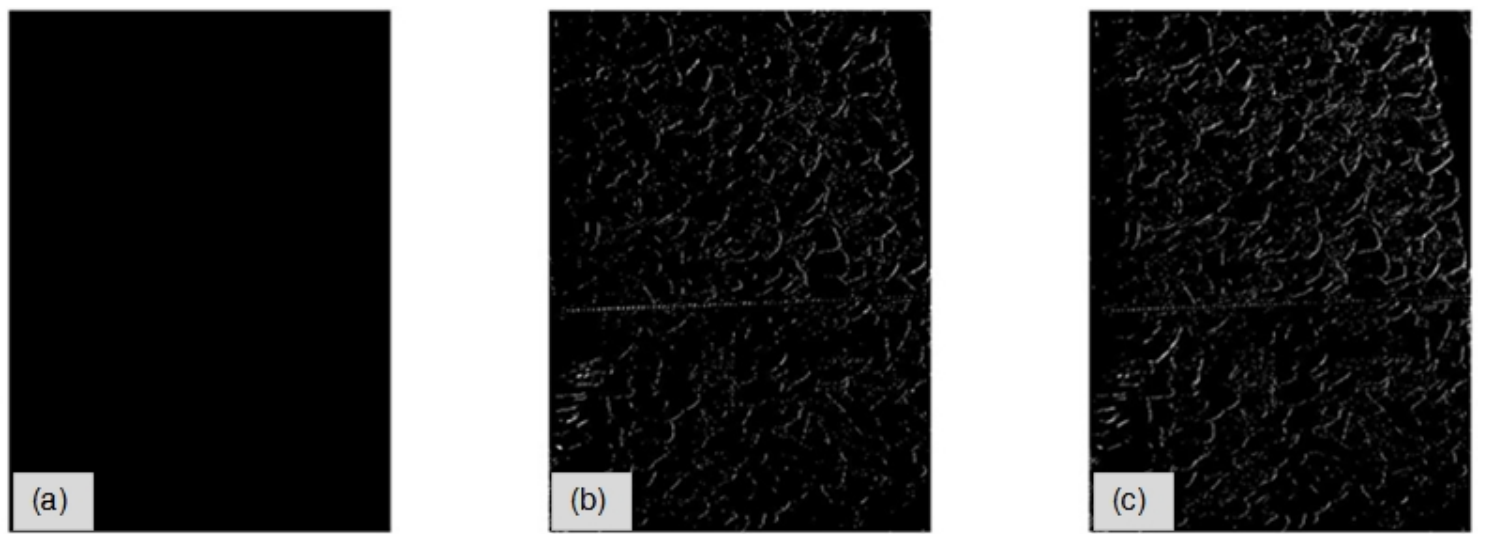

Figure 17: Representation of ballast grain movements on the shoulder slope (a) prior to testing, (b) during harvesting the data at $\mathbf{0 . 2 5}$ million loading cycles and (c) the end of the RPS test 


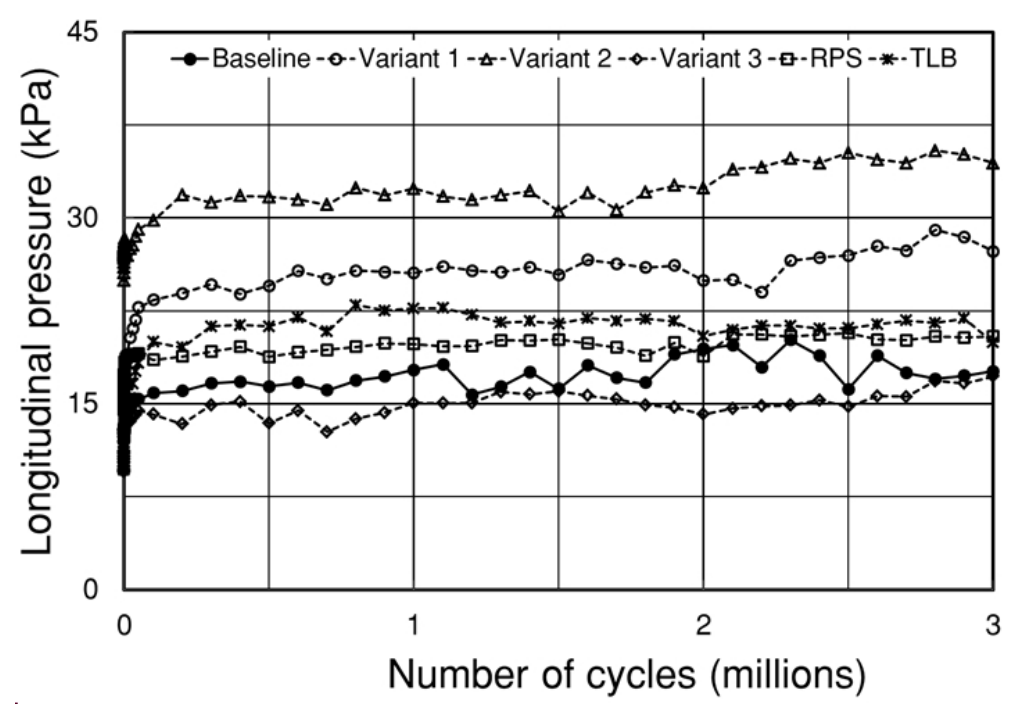

Figure 18: Maximum longitudinal stress Vs. loading cycles: pressure plate 1 (sleeper middle)

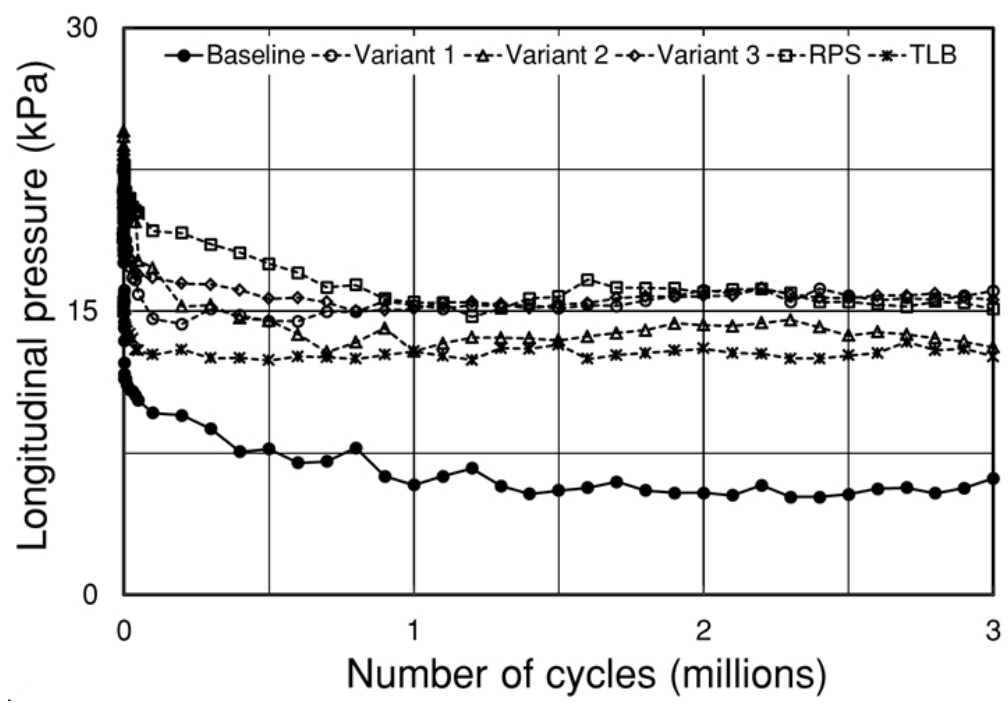

Figure 19: Maximum longitudinal stress Vs. loading cycles: pressure plate 4, (sleeper end) 